\title{
Impact of Storage Method on the Chemical and Physical Properties of Poplar Wood from Short-Rotation Coppice Stored for a Period of 9 Months
}

\author{
Björn Günther ${ }^{1}$ D $\cdot$ Nicole Starke ${ }^{1} \cdot$ Armin Meurer $^{1} \cdot$ C.-T. Bues ${ }^{1} \cdot$ Steffen Fischer $^{2} \cdot$ Martina Bremer $^{2} \cdot$ Maren Freese $^{2}$
}

Received: 7 July 2020 / Accepted: 9 December 2020 / Published online: 21 December 2020

(C) The Author(s) 2020

\begin{abstract}
In addition to the use as biofuel, the utilization of poplar wood as a raw material from short-rotation coppice (SRC) became increasingly important in recent years. Because poplar SRCs are harvested during dormant season, wood storage is of particular importance to guarantee wood processing industries a continuous wood supply. The study focuses on the change of physical and chemical properties of poplar wood by the application of different storage strategies over a 9-month period. Therefore, a total amount of $60 \mathrm{~m}^{3}$ test log piles were set up in 2018 for six different storage variants: compact piles, compact piles with water sprinkling and oxygen exclusion, each with logs in bark and debarked. The effects on wood moisture content, equilibrium moisture content and wood density $\left(\rho_{0}\right)$ and the changes in the chemical components lignin, cellulose, hemicellulose and extracts were determined and evaluated. As expected, the wood moisture content changed in a wide range over the storage period, depending on the variant. The levels of equilibrium moisture (changes from $-4 \%$ to $-13.1 \%$ ) as well as wood density (changes from $-2.61 \%$ to $-9.01 \%$ ) decreased for all variants between start and end of storage. Changes in chemical composition were observed for all storage variants, which indicates microbial activity supporting the assumption that the observed mass loss is driven by wood decay. Overall, changes were more homogeneous for logs in compact piles compared to the other storage methods. Considering the weather conditions during the investigated period, the results indicate that storage in compact piles with debarked logs is the best method for the conservation of poplar wood from SRC.
\end{abstract}

Keywords Log storage $\cdot$ Short-rotation coppice $\cdot$ Poplar $\cdot$ Storage methods $\cdot$ Wood moisture content $\cdot$ Dry matter loss $\cdot$ Physical wood properties $\cdot$ Chemical wood properties

\section{Introduction}

While importance of poplar wood production from shortrotation coppice (SRC) [1] increased in the last decades [2, $3]$, it was primarily focused on the supply for the energy sector. Utilization of these timbers as raw materials is reasonable against the backdrop of medium-term sequestration of $\mathrm{CO}_{2}$ [4]. Taking into account existing approaches for poplar wood utilization $[4,5]$, the fabrication of particle boards from chipped wood is particularly promising [5].

Björn Günther

bjoern.guenther@tu-dresden.de

1 Chair of Forest Utilization, Institute of Forest Utilization and Technology, Technische Universität Dresden, Pienner Straße 19, 01737 Tharandt, Germany

2 Institute of Wood and Plant Chemistry, Technische Universität Dresden, Pienner Straße 19, 01737 Tharandt, Germany
Associated with the material use, new challenges regarding harvesting technologies and logistics to fit the special requirements of SRCs occur, such as the limitation of harvesting periods to the dormant season in winter [6] leaving only a few months for direct processing. The requirement of constant supply for wood processing industries throughout the year therefore demands appropriate storage methods. Numerous studies were carried out for wood chips [7, 8], whereas storage of logs from SRCs received less attention in research $[9,10]$. The majority of recent investigations about log storage methods relate to calamity wood from forests, which leads to a focus on other wood species than poplar [10-13]. The main goal for the application of an adequate storing method is to preserve the physical properties (e.g. wood density) and other quality-related characteristics (e.g. colour) of wood for its further utilization $[10,13,14]$.

During storage, the roundwood is exposed to decay. In particular, the dangers associated with the microbial activity of wood-destroying fungi and bacteria should be mentioned [15-18]. These usually lead to a partial reduction in the value 
of the wood; in extreme cases, the roundwood can even be completely devalued. This risk is particularly high for trees with a very low durability, such as poplar [19].

The mass loss reveals the influence of these threats in a congruous and comparable way. For poplar wood chips, a monthly mass loss between 1.4 and $4.2 \%$ was observed during storage [20]. Overall losses depend on the used compartments of the tree, whereby consistently higher reductions can be expected for chips from stems than for those from crown wood [21]. Large differences in mass losses for 7-month open air storage period of poplar were found between wood chips and logs and ranged between 17 to $19 \%$ and 4 to $7 \%$, respectively $[13,22]$.

Since different threats to the wood quality are expected, depending on the duration of roundwood storage, different storage strategies are necessary, which are related to the development of wood moisture content, unfavourable for fungal growth [23].

A general differentiation is made between procedures for short-term (a few weeks) and medium- to long-term storage (a few months to several years) [13].

Considering the demands in the case of raw material supply from SRCs, the application of procedures for medium- to long-term storage of logs seems to be reasonable. Therefore, the scope of this study was to evaluate different methods for the storage of poplar (Populus nigra L x P. maximowiczii $\mathrm{H}$.) logs over a period of up to 9 months. Three storage methods, (a) storage in compact pile, (b) storage in compact pile with water sprinkling and (c) log conservation under oxygen exclusion, have been tested and evaluated regarding their impact on the physical properties (wood moisture content, equilibrium moisture content and wood density $\left.\left(\rho_{0}\right)\right)$ and chemical composition. All tests were carried out for logs with and without bark.

\section{Materials and Methods}

\section{Experimental Setup}

The investigation was carried out in 2018 from March to November in the test facility of the Technische Universität Dresden (TUD) and Staatsbetrieb Sachsenforst (SBS) in the Tharandter Wald near to Grillenburg, southeast Germany (Table 1). For the storage setup, approximately 600 trees were harvested with an age between 8 and 12 years throughout February 2018 from an SRC in Thammenhain near Leipzig, Germany. A total of 223 poplar wood sections from the poplar clone Max 1, Populus nigra L $x$ P. maximowiczii $\mathrm{H}$., with a length of $4 \mathrm{~m}$ and a mean diameter of $138 \mathrm{~mm}$ were selected for further analyses.

Six different storage variants were assessed: storage in compact piles (CP), with and without bark (CPwb/CPwob); storage with water sprinkling (WS), with and without bark (WSwb/WSwob); and storage under oxygen exclusion (OE), with and without bark (OEwb/OEwob).

For the storage variants $\mathrm{CPwb} /$ wob and WSwb/wob, the pile sizes varied between 8 and $18 \mathrm{~m}^{3}$ (pile dimension varied between approx. $4 \mathrm{~m} \times 3 \mathrm{~m} \times 0.9 \mathrm{~m}$ and $4 \mathrm{~m} \times 4.5 \mathrm{~m} \times 1 \mathrm{~m}$ ). Whereby a larger pile was set up for CPwb since more heterogeneous condition were anticipated for this variant.

For the OE variants, the amount of wood was separated into ten single packages of equal sizes, whereby some packages were used as backup (risk of possible damages) and for long-term investigations (ongoing). Different harvesting dates led to postponement of the starts of storage for the different variants (Table 2).

The logs stored in compact piles were placed on vegetation-free gravel. Some logs were used as underlayers to ensure ventilation, supporting a faster drying process. The two piles for storage under water sprinkling were sprinkled continuously with $5 \mathrm{l} / \mathrm{m}^{3} / \mathrm{h}$ on both end faces and from the shell surface. The required fresh water was pumped out of a pond next to the piles. A plastic coverage was placed under the piles to regulate water runoff, avoid uncontrolled growth of vegetation and prevent the logs from sinking into the soil. For storage under oxygen exclusion, the piles were double-sealed with a silage film and secured with a geogrid avoiding damage by mice, since the packages were placed on grassland.

\section{Sampling Strategies}

The sampling strategies varied in terms of sampling intervals, number of samples and analyses carried out. With the start of storage, stem discs were taken $20 \mathrm{~cm}$ from the base of the log to avoid the influence of drying effects between harvesting and sampling while ensuring integrity throughout storage.

To determine the development of wood moisture content, additional samples were taken shortly after the experimental setup was established and at the end of the growing season, on logs of representative positions within the piles (top, mid and base layer). Although different starting dates for the storage variants were necessary, this approach was chosen to synchronize the observation of wood moisture content with weather conditions. Thereby approximately $7 \mathrm{~g}$ of particles was gathered by chainsaw from each sampled log, to minimize the impact on the stored logs. A previous comparison of different extraction methods (particles and cores of different sizes) with stem discs showed that the chosen procedure delivers similar and reproduceable values. Furthermore this approach is based on a standard procedure to determine wood moisture content in the wood processing industry [24, 25]. Additional sampling was not possible for storage under oxygen exclusion without destroying the film or negative impact on the storage gas atmosphere within the piles. 
Table 1 Characterization of the storage location and sample material

\begin{tabular}{lll}
\hline Storage location & & Tharandter Wald, Grillenburg, Germany \\
& Longitude & $13^{\circ} \mathrm{E} 28^{\prime} 47.42$ \\
& Latitude & $50^{\circ} \mathrm{N} 58^{\prime} 46.34$ \\
& Location altitude & $350 \mathrm{~m}$ above sea level \\
Species & & Populus nigra $\mathrm{L} x$ P. maximowiczii $\mathrm{H}$ \\
Clone & Code & Max1 \\
Harvesting date & & February 2018 \\
Start of storage (SoS) & March/April 2018 \\
Additional sampling (AS) & May/October 2018 \\
End of storage (EoS) & November/December 2018 \\
Storage volume & & 8 to $18 \mathrm{~m} \mathrm{~m}^{3}$ per storage variant \\
Number of sampled logs & 223 \\
Log length & & $4 \mathrm{~m}$ \\
Diameter & & $138 \mathrm{~mm}$ \\
& & $25.6 \mathrm{~mm}$ \\
\hline
\end{tabular}

For the sampling at the end of storage, it was possible to take discs from the middle of the logs, to reduce the influence of boundary effects.

The components of the gas atmosphere $\left(\mathrm{CO}_{2}\right.$ and $\left.\mathrm{O}_{2}\right)$ were regularly measured using the Geotechnical Instrument gas analyser (Anagas CD 95, model: 1/9; manufactured by Geotechnical Instruments, Leamington Spa, UK) [13, 26].

Various physical, chemical and wood biological analyses were carried out to evaluate the individual storage processes with regard to changes in the wood properties between begin and end of the storage period (Table 3 ).

\section{Physical Properties}

Wood moisture content (WMC) on oven-dry basis was determined gravimetric from stem discs (SoS, EoS) and particles (AS) according to the standard EN 13183-1 [27]. Stem discs were weighted, oven-dried till mass constancy and weighted again. Whereas the moisture content for the particles (AS) was determined with an infrared moisture analyser (Mettler Toledo LP16, Mettler-Toledo AG, Greifensee, Switzerland), delivering precise data for small samples.
Oven-dry density $\left(\rho_{0}\right)$ was determined according to the standard DIN 52182 [28]. Therefore, 329 specimens from 164 stem discs, which were previously used for the WMC determination, were produced. These were taken from $82 \operatorname{logs}$ sampled twice (SoS and EoS). If possible, depending on disc size and damages (cracks, branches, etc.), at least two and up to six cuboid specimens with sides larger than $2 \mathrm{~cm}$ were shaped.

Equilibrium moisture content (EMC) was determined from specimens which were used previously for dry density determination; therefore, the specimens were in the state of water adsorption. The specimens were conditioned at $20{ }^{\circ} \mathrm{C}$ and relative humidity of $65 \%$ (20/65 standard atmosphere for conditioning and/ or testing [29]) until a constant mass level was reached, and then moisture content according to EN 13183-1 [27] was determined.

Measurements for oven-dry density and EMC were carried out with high precision scale (Sartorius QUNITIX124-1S, Sartorius Lab Instruments $\mathrm{GmbH} \& \mathrm{Co}$. KG, Göttingen, Germany) and calliper (Mitutoyo CDN-P30, Mitutoyo Corporation, Takatsu-ku, Japan).

\section{Chemical Analysis}

For the analysis of the chemical composition, a total amount of 69 specimens, previously used for the determination of the

Table 2 Specifications for the experimental pile setup for the different storage variants

\begin{tabular}{|c|c|c|c|c|c|}
\hline Storage variant & Number of logs & Sampled logs & Start of storage & Additional sampling & End of storage \\
\hline Compact pile with bark & 205 & 73 & 27.03 .18 & $24.05 .18 / 10.10 .18$ & 03.12 .18 \\
\hline Compact pile without bark & 98 & 61 & 07.03 .18 & $24.05 .18 / 10.10 .18$ & 06.11 .18 \\
\hline Compact pile with water sprinkling with bark & 64 & 34 & 14.03 .18 & $24.05 .18 / 10.10 .18$ & 14.11 .18 \\
\hline Compact pile with water sprinkling without bark & 41 & 20 & 03.04 .18 & $24.05 .18 / 10.10 .18$ & 12.12 .18 \\
\hline Log conservation under oxygen exclusion with bark & 102 & 12 & 01.03 .18 & - & 12.11 .18 \\
\hline Log conservation under oxygen exclusion without bark & 81 & 8 & 27.03 .18 & - & 12.12 .18 \\
\hline
\end{tabular}


Table 3 Overview of the analysis carried out for each storage method and the associated sampling strategies

\begin{tabular}{|c|c|c|}
\hline Storage method & Analysis & Sample strategy (sample numbers) \\
\hline \multirow[t]{5}{*}{ Compact piles (with and without bark) } & Wood moisture content $(\omega)$ & SoS and $\operatorname{EoS}(143)+2 \times$ AS (40) \\
\hline & Wood density $\left(\rho_{0}\right)$ & SoS and EoS (67) \\
\hline & Chemical analysis & SoS and EoS (24) \\
\hline & Fungi infection (micro-/macroscopic) & Selected logs EoS \\
\hline & Equilibrium moisture content (EMC) & SoS and EoS (112) \\
\hline \multirow{5}{*}{$\begin{array}{l}\text { Compact piles with water sprinkling } \\
\text { (with and without bark) }\end{array}$} & Wood moisture content $(\omega)$ & SoS and $\operatorname{EoS}(186)+2 \times$ AS (20) \\
\hline & Wood density $\left(\rho_{0}\right)$ & SoS and EoS (68) \\
\hline & Chemical analysis & SoS and EoS (26) \\
\hline & Fungi infection (micro-/macroscopic) & Selected logs EoS \\
\hline & Equilibrium moisture content (EMC) & SoS and EoS (72) \\
\hline \multirow{5}{*}{$\begin{array}{l}\text { Log conservation under oxygen exclusion } \\
\text { (with and without bark) }\end{array}$} & Wood moisture content $(\omega)$ & SoS and EoS (24) \\
\hline & Wood density $\left(\rho_{0}\right)$ & SoS and EoS (29) \\
\hline & Chemical analysis & SoS and EoS (19) \\
\hline & $\begin{array}{l}\text { Gas analysis }\left(\mathrm{CO}_{2} / \mathrm{O}_{2} \text { concentration }\right. \\
\text { within the sealed pile })\end{array}$ & Monthly, all piles \\
\hline & Equilibrium moisture content (EMC) & SoS and EoS (39) \\
\hline
\end{tabular}

physical properties, was selected. For this purpose, representative bulk samples were created for each storage variant and ground together $(<1 \mathrm{~mm})$. Measurements were carried out twice on the same bulk sample.

The dry mass of the samples was determined at $103^{\circ} \mathrm{C}$. All values mentioned for composition refer to the dry mass. Furthermore, the determined component stops for EoS were corrected with the mass loss determined by the change in oven-dry densities during storage. Gravimetric determination was carried out with a high precision scale (Sartorius QUNITIX124-1S, Sartorius Lab Instruments GmbH \& Co. KG, Göttingen, Germany).

\section{Determination of Extract Content}

About $5 \mathrm{~g}$ of each bulk sample was extracted in a Soxhlet apparatus with $200 \mathrm{~mL}$ of a 1:1 mixture of ethanol and toluene

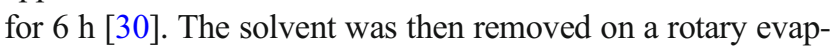
orator. Afterwards, the remaining extracts were dried at $103{ }^{\circ} \mathrm{C}$.

\section{Determination of Holocellulose Content}

Approximately $0.5 \mathrm{~g}$ of each extracted sample was mixed in an Erlenmeyer flask with $60 \mathrm{~mL}$ of water, $100 \mu \mathrm{L}$ of glacial acetic acid and $0.5 \mathrm{~g}$ of sodium chlorite. The mixture was then shaken at $70{ }^{\circ} \mathrm{C}$ for $1 \mathrm{~h}$. Then $100 \mu \mathrm{L}$ of glacial acetic acid and $0.5 \mathrm{~g}$ of sodium chlorite were again added and shaken once more at $70^{\circ} \mathrm{C}$ for $1 \mathrm{~h}$. This treatment was repeated five times. After cooling, the remaining holocellulose was separated using a glass filter (porosity $40 \mu \mathrm{m}$ ), washed acid-free with deionized water and then dried at $103{ }^{\circ} \mathrm{C}$ [31].

\section{Determination of Cellulose Content}

Approximately $1 \mathrm{~g}$ of each extracted sample was boiled three times under reflux in $25 \mathrm{~mL}$ of a nitration mixture $(10 \mathrm{~mL}$ $65 \% \mathrm{HNO}_{3}+40 \mathrm{~mL} 96 \%$ ethanol) for $1 \mathrm{~h}$. After each step, the samples were separated by filtration, and the boiling step was repeated with fresh nitration mixture. The solid residue after the third step was washed with ethanol and water and then boiled again under reflux in $100 \mathrm{~mL}$ deionized water for $30 \mathrm{~min}$. Finally, the resulting cellulose was separated using a glass filter (porosity $40 \mu \mathrm{m}$ ), washed acid-free with deionized water and then dried at $103{ }^{\circ} \mathrm{C}[32]$.

\section{Determination of Hemicelluloses}

The content of hemicelluloses was determined as the difference between holocellulose and cellulose.

\section{Determination of Klason Lignin Content}

Approximately $0.5 \mathrm{~g}$ of each extracted samples was mixed with $20 \mathrm{~mL}$ of $72 \%$ sulphuric acid. The mixture was stirred at room temperature for $2 \mathrm{~h}$. After that, the mixture was diluted with deionized water to a final volume of $650 \mathrm{~mL}$. This solution was boiled under reflux for $4 \mathrm{~h}$. The insoluble lignin was separated using a glass filter (porosity $16 \mu \mathrm{m}$ ) after cooling down. The lignin was washed acid-free with hot deionized water and dried at $103{ }^{\circ} \mathrm{C}$. 


\section{Fungi Infestation}

Throughout the storage period, different fruit bodies appeared on the logs stored in compact piles and those under water sprinkling. Towards the EoS, selected samples were taken from visibly infected logs. Selected segments were documented macroscopically and the occurring fungi identified, as far as possible.

For qualitative analysis, $20 \mu \mathrm{m}$ thin slices were cut using a sledge microtome from cross-, radial and tangential anatomical sections. In order to increase contrast and identify fungi hyphae, the thin sections were stained by Astra blue, for the not lignified tissue and safranin and for the lignified tissue.

For the piles under oxygen exclusion, no samples were taken.

\section{Data Analysis}

The data was normally distributed, as assessed by the (Kolmogorov-Smirnov) Lilliefors and the Shapiro-Wilk test. Since the normality assumption was not violated, parametric statistic was applied. Significant differences between start and end of storage for WMC, EMC and wood density were tested using paired two-sample $t$ test, while a significance level of 5\% was applied $(\alpha=0.05)$. The analysis was run in SPSS ${ }^{\circ}$ (version 26).

To evaluate the magnitude of the influence of the storage method on the respective wood property, the effect size based on Pearson's $r$ was calculated using the $T$ value and the degrees of freedom. The six storage methods were sorted by the absolute values of the effect size. Whereby the rank six describes the strongest and rank one the weakest influence.

\section{Results}

\section{Weather Conditions}

The weather conditions over the storage period 2018 were recorded by the Chair of Meteorology, TUD, as shown in Fig. 1. Taking into account that the water sprinkling ran constantly throughout the storage and piles in film maintained an isolated atmosphere, only the storage in compact piles was strongly influenced by weather.

The mean monthly air temperature was $10.9{ }^{\circ} \mathrm{C}$, and the average monthly amount of precipitation was $42 \mathrm{~mm}$ during the storage period 2018 , which was a $2.3 \mathrm{~K}$ higher temperature and $42 \%$ lower precipitation compared to long-term weather data (1961-1990).

\section{Gas Atmosphere Inside the Sealed in Film}

Precondition for a proper log storage under oxygen exclusion was a rapid reduction of the oxygen content in the wrapped piles by microbiotic activities and its constant maintenance during the whole storage period. Depending on the storage variant (with or without bark), differing developments of the gas atmosphere were observed (Fig. 2).

For logs without bark stored under oxygen exclusion, the oxygen-free atmosphere was reached after 3 weeks, while $\mathrm{CO}_{2}$ first increased from 9 to $35 \%$ after 13 weeks, followed by a reduction reaching a concentration of $13 \%$ at the end of storage. For logs with bark, the reduction of oxygen and the increase of $\mathrm{CO}_{2}$ were much faster (oxygen-free atmosphere after 1 week, $\mathrm{CO}_{2}$ increase from 3 to $33 \%$ after 7 weeks, followed by a decrease to $6 \%$ towards the end of storage).

\section{Wood Moisture Content}

All storage variants have shown significant $(p$ value $<.01)$ changes in wood moisture content (WMC) at the end of the storage period 2018 (Table 4).

For storage under drying conditions, the WMC was reduced to $74 \%$ (CPwb) and 20\% (CPwob), whereas for storage with water sprinkling with and without bark, the WMC was increased to $163 \%$ (WSwb) and 248\% (WSwob), respectively. Similar effects were detected for storage under oxygen exclusion (OEwb 155\%; OEwob 156\%).

Wood moisture content varied for piles with additional sampling between different sampling dates. Between the first and the second additional sampling, WMC changed from 38 to $98 \%$ for $\mathrm{CPwb}$, from 17 to $35 \%$ for CPwob, from 187 to $155 \%$ for WSwb and from 114 to $185 \%$ for WSwob.

\section{Wood Density}

All storage variants have shown a wood density reduction over the storage time of 9 months (Fig. 3). Significant differences were found for both storage variants with water sprinkling and under oxygen exclusion $(p$ value $<.01)$. The highest dry mass loss $(-9.01 \%)$ was found in logs without bark stored with water sprinkling (WSwob). The lowest density reduction $(-2.61 \%)$ was found for storage under oxygen exclusion with bark (OEwb). All other storage variants showed decreases in density between 4.81 and $6.53 \%$. Over all variants, storage without bark showed higher density reductions.

\section{Equilibrium Moisture Content}

The equilibrium moisture content (EMC) at $20{ }^{\circ} \mathrm{C}$ and $65 \%$ relative humidity (20/65) decreased after 9 months of storage by an average of $9 \%$ for all variants (Fig. 4). The reduction of the EMC for logs stored with water sprinkling and under oxygen exclusion was higher compared to logs stored in compact piles (CPwb, $-4 \%$; CPwob, $-6.5 \%$; WSwb, $-8.5 \%$; WSwob, $-8.8 \%$; OEwb and OEwob, $-13.1 \%)$. The differences between SoS and EoS were highly significant ( $p$ value $<.001)$ for all storage variants. 
Fig. 1 Weather data during the storage period 2018 versus longterm weather data (1961-1990), recorded by Chair of Meteorology, TUD, weather station Grillenburg
Grillenburg: $385 \mathrm{~m}$ above sea level, $50^{\circ} 57 \mathrm{~N}, 13^{\circ} 29 \mathrm{E}$

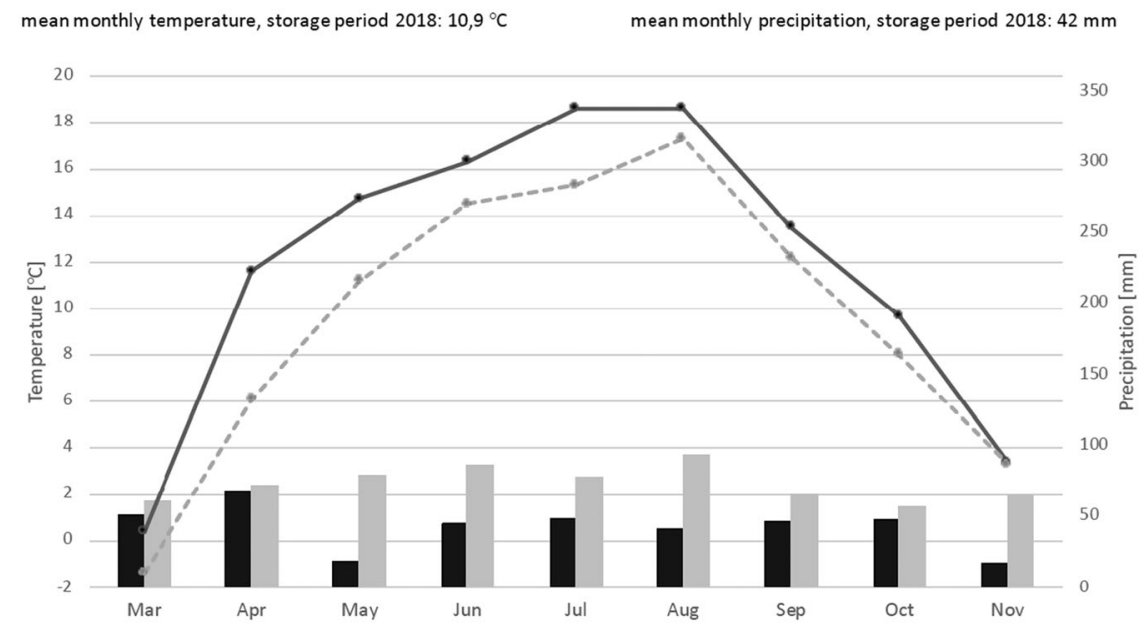

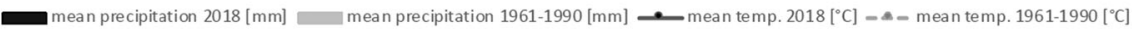

\section{Chemical Composition}

The change in the chemical composition of the wood due to storage depends both on the storage variant and the debarking (Fig. 5, Table 5). Except for extractives in OEwb, the share of wooden components decreases for all storage variants. In the case of CP and WSwb, this is done with medium intensity and relatively proportionally to the initial content of the individual components. The greatest overall reductions were found in WSwob especially for cellulose and hemicelluloses $(-2.62$ and $-4.34 \%$, resp.). For OE variants, the overall reductions were low, whereas reductions in lignin were the lowest (wb,$0.32 \%$; wob, $-0.17 \%$ ). Noteworthy is the primary reduction of cellulose for OEwb $(-2.26 \%)$, whereas the debarked variant shows higher reductions of hemicelluloses $(-3.10 \%)$.

For the debarked variants, reductions in extractives and hemicelluloses were higher. This difference was also observed for cellulose in CP and WS, but inverses for OE. Another difference is the greater lignin breakdown when stored with bark, but for OE, the differences are small and in the error range of the method. It is striking that the reduction of hemicelluloses in OEwb is very low. Homogeneous changes were
Fig. 2 Development of $\mathrm{O}_{2} / \mathrm{CO}_{2}$ concentration within the sealed packages over 9 months for OEwb and OEwob

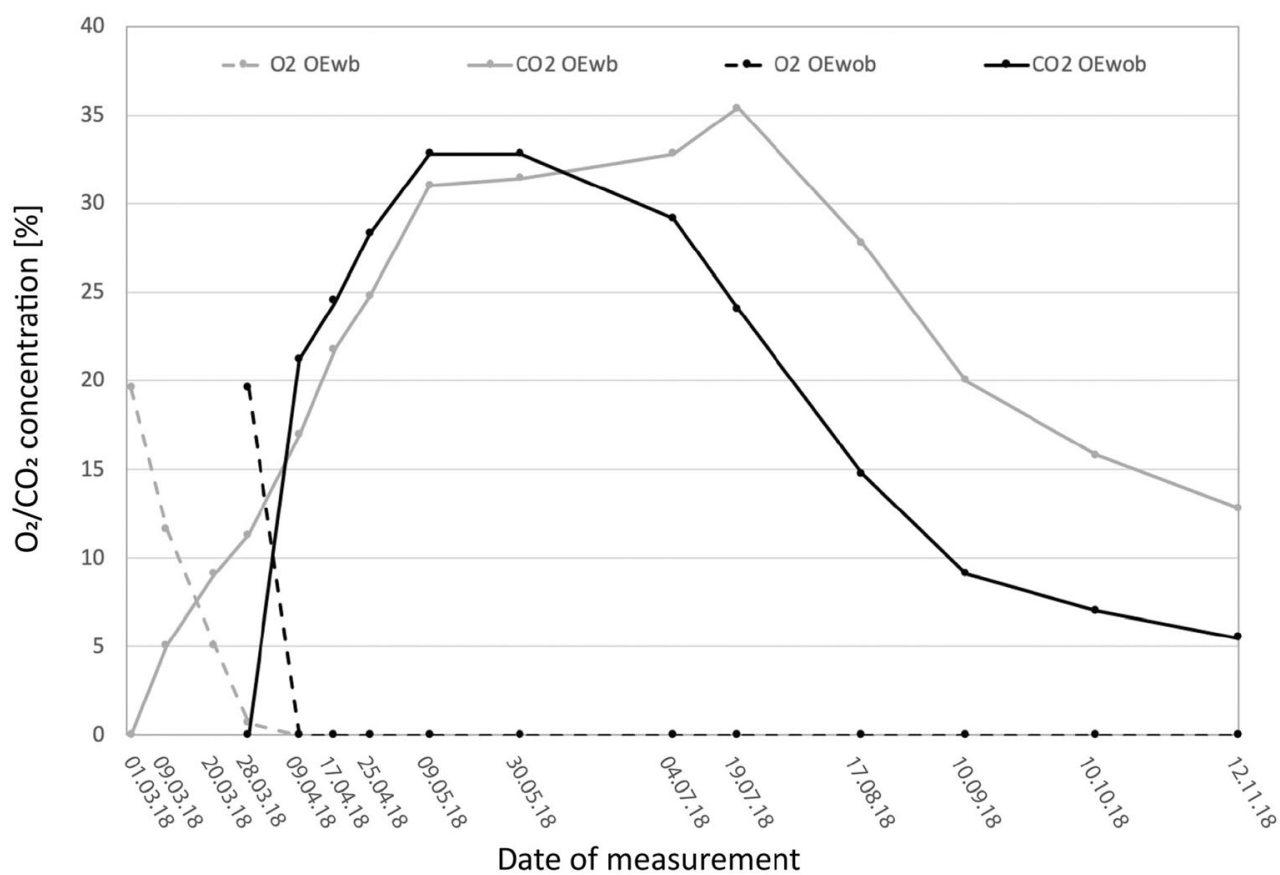


Table 4 Changes in wood moisture content (WMC) for the 9-month storage for the different storage variants

\begin{tabular}{|c|c|c|c|c|c|c|c|c|c|c|c|c|c|}
\hline \multirow[b]{2}{*}{ Variant } & \multicolumn{3}{|l|}{ SoS } & \multicolumn{3}{|l|}{ 1. Sampling } & \multicolumn{3}{|l|}{ 2. Sampling } & \multicolumn{3}{|l|}{ EoS } & \multirow[b]{2}{*}{ Change (\%) } \\
\hline & WMC (\%) & SD & $N$ & $\mathrm{WMC}(\%)$ & SD & $N$ & WMC (\%) & SD & $N$ & WMC (\%) & $\mathrm{SD}$ & $N$ & \\
\hline CPwb & 139.72 & 10.84 & 78 & 38.32 & 19.44 & 10 & 97.51 & 25.78 & 10 & 73.51 & 23.39 & 77 & -66.22 \\
\hline CPwob & 141.09 & 10.57 & 65 & 17.47 & 6.13 & 10 & 35.14 & 16.12 & 10 & 19.49 & 2.33 & 65 & -121.60 \\
\hline WSwb & 136.59 & 9.13 & 37 & 187.19 & 32.29 & 6 & 154.93 & 13.02 & 6 & 163.47 & 39.60 & 37 & 26.87 \\
\hline WSwob & 153.88 & 7.77 & 22 & 213.55 & 13.92 & 4 & 184.56 & 13.13 & 4 & 248.79 & 14.86 & 22 & 94.91 \\
\hline OEwb & 139.08 & 9.91 & 12 & & & & & & & 155.23 & 27.87 & 12 & 16.15 \\
\hline OEwob & 135.29 & 11.53 & 8 & & & & & & & 155.61 & 34.35 & 8 & 20.32 \\
\hline
\end{tabular}

observed for storage variants under drying conditions in comparison to those under wet conditions.

The accumulated percentages per variant were between 96.06 and $104.82 \%$, closely surrounding the ideal theoretical $100 \%$.

\section{Fungi Infestation}

Fungi infestation is a main risk regarding log storage. Particularly wood quality and dry mass loss, indicated by a reduction in wood density, are influenced significantly by wood-destroying fungi $[14,17]$. Four widespread fungi species could be identified, from which three are white-rot fungi (Schizophyllum commune Fr., Cylindrobasidium evolvens Fr., Chondrostereum spec.), mainly breaking down lignin, and one bark fungus (Neonectria coccinea DESM.).

The logs stored in compact piles under drying conditions showed severe infestation by white rot causing fungi, foremost Schizophyllum commune, whereas fruit bodies on logs in piles with water sprinkling were rarely found. For each storage variant, logs with bark showed higher infestation rates than those without.

\section{Discussion}

\section{Methodical Approach}

The experimental setup of this investigation was chosen according to the evaluation of different methods for the storage of poplar logs from SRC. Therefore, trees with representative age and diameter were selected. Pile sizes were adjusted to the anticipated storage conditions. For storage under drying conditions, especially for CPwb, slightly larger piles were set up with the intention to reduce boundary effects and realize reasonable conditions inside the pile. Findings about the low correlation of drying behaviour and pile heights are not completely applicable, since significantly larger pile dimensions were investigated here [13]. Therefore, a strong influence of boundary effects could not be prevented by the chosen
Fig. 3 Changes in wood density $\left(\rho_{0}\right)$ for the 9-month storage period for the different storage variants

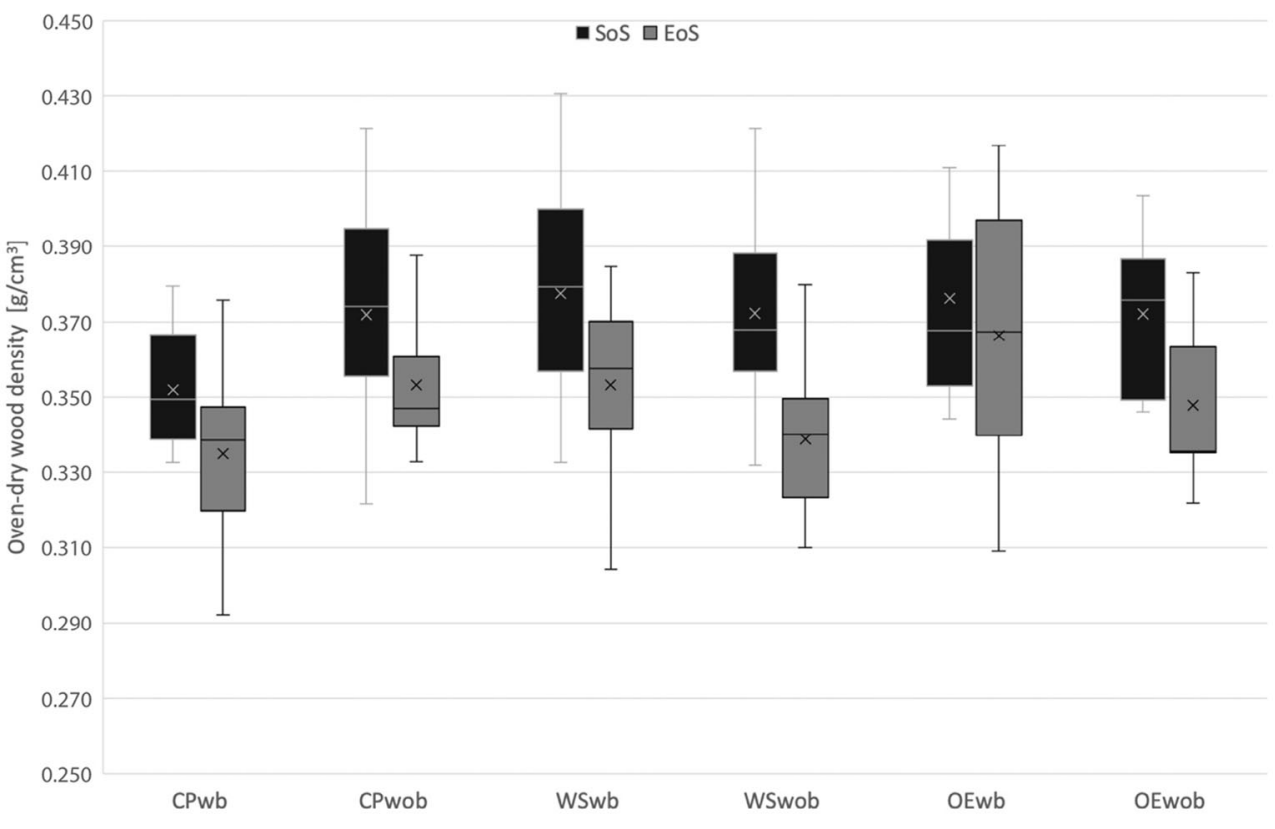


Fig. 4 Changes in equilibrium moisture content $(20 / 65)$ for the 9-month storage period for the different storage variants

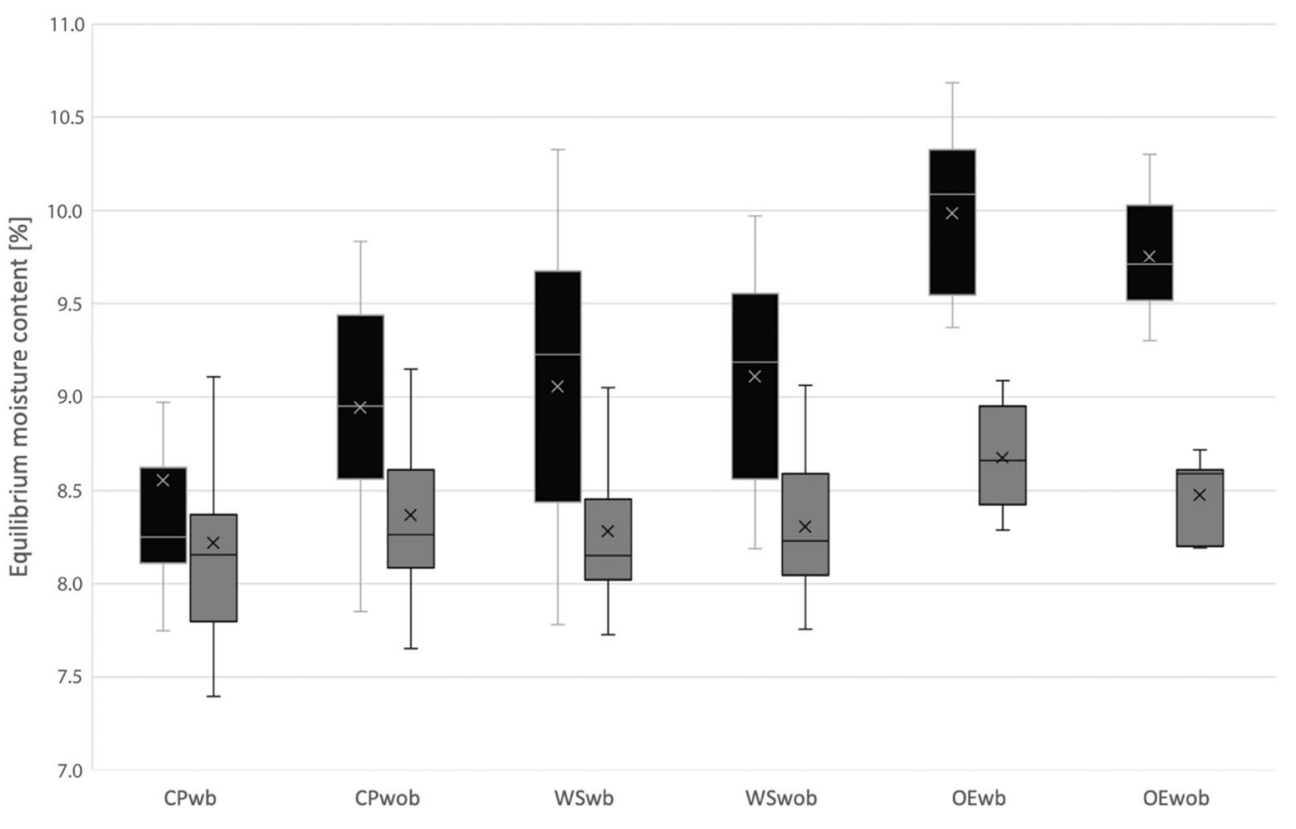

experimental setup for $\mathrm{CP}$, and the transferability of the findings in practice is limited by this.

Since the water sprinkling is expected to create homogeneous conditions for all stored logs, smaller storage volumes were used, because these variants should be less affected by pile size. This assumption is also valid for storage under oxygen exclusion, due to the closed atmosphere. Regarding the setup for these methods (WS, OE), the conditions can therefore be assumed as comparable to those in common practice.

Although investigations determined relevant differences for wood moisture development, mass losses and changes in chemical compositions depending on sampling location [21, $33,34]$, the chosen extraction points on one log were inside a range of $2 \mathrm{~m}$. Considering the age, diameter and differences in cambial age, the positive effect of lower spatial distance would not compensate the boundary effects, e.g. drying and fungal infestation starting on the log ends.

The stored logs were harvested throughout February resulting in prolonged possible starting dates for the begin of storage. To ensure representative and comparable storage lengths of 9 months for all variants, the end of storage was extended for some piles. Since all logs were stored throughout the growing season with weather conditions, favourable for fungi growth and wood decay, the chosen approach seems reasonable. To overcome the resulting limits of different sampling dates at start and end of storage, additional sampling was applied at the begin and towards the end of the growing season.

All samples for the analysis of chemical composition were previously oven-dried at $103{ }^{\circ} \mathrm{C}$ for the determination of wood

Table 5 Chemical composition at SoS and EoS corrected by mass loss after 9-month storage for the different storage variants (mean \pm deviation)

\begin{tabular}{|c|c|c|c|c|c|c|c|c|}
\hline Storage variant & Sampling & Mass loss (\%) & Extracts $(\%)$ & Lignin $(\%)$ & Cellulose (\%) & Hemicelluloses (\%) & Ash (\%) & Total (\%) \\
\hline \multirow[t]{2}{*}{ CPwb } & SoS & & $3.14 \pm 0.10$ & $21.55 \pm 0.09$ & $47.54 \pm 0.25$ & $30.89 \pm 0.58$ & 0.83 & 103.95 \\
\hline & EoS & -4.8 & $2.83 \pm 0.06$ & $19.35 \pm 0.05$ & $46.42 \pm 0.13$ & $29.40 \pm 0.39$ & 0.86 & 97.44 \\
\hline \multirow[t]{2}{*}{ CPwob } & SoS & & $3.80 \pm 0.14$ & $21.92 \pm 0.09$ & $46.58 \pm 0.28$ & $30.82 \pm 0.04$ & 0.77 & 103.89 \\
\hline & EoS & -5.1 & $2.79 \pm 0.01$ & $21.35 \pm 0.33$ & $44.67 \pm 0.12$ & $29.26 \pm 0.52$ & 0.50 & 98.57 \\
\hline \multirow[t]{2}{*}{ WSwb } & SoS & & $3.01 \pm 0.11$ & $21.09 \pm 0.28$ & $48.45 \pm 0.43$ & $30.48 \pm 0.04$ & 0.94 & 104.82 \\
\hline & EoS & -6.6 & $2.89 \pm 0.06$ & $19.19 \pm 0.23$ & $47.32 \pm 0.30$ & $28.47 \pm 0.14$ & 0.89 & 98.76 \\
\hline \multirow[t]{2}{*}{ WSwob } & SoS & & $2.83 \pm 0.05$ & $19.95 \pm 0.24$ & $47.97 \pm 0.34$ & $32.82 \pm 0.16$ & 0.72 & 104.29 \\
\hline & EoS & -8.8 & $2.62 \pm 0.06$ & $18.98 \pm 0.19$ & $45.35 \pm 0.27$ & $28.48 \pm 0.23$ & 0.63 & 96.06 \\
\hline \multirow[t]{2}{*}{ OEwb } & SoS & & $2.92 \pm 0.05$ & $21.24 \pm 0.23$ & $47.35 \pm 0.50$ & $32.43 \pm 0.12$ & 0.85 & 104.79 \\
\hline & EoS & -2.7 & $3.11 \pm 0.08$ & $20.92 \pm 0.22$ & $45.09 \pm 0.11$ & $32.24 \pm 0.27$ & 0.85 & 101.62 \\
\hline \multirow[t]{2}{*}{ OEwob } & SoS & & $3.53 \pm 0.02$ & $20.22 \pm 0.10$ & $47.61 \pm 0.37$ & $30.56 \pm 0.64$ & 0.70 & 102.62 \\
\hline & EoS & -6.5 & $2.77 \pm 0.01$ & $20.05 \pm 0.31$ & $46.71 \pm 0.51$ & $27.46 \pm 0.38$ & 1.08 & 98.06 \\
\hline
\end{tabular}


Fig. 5 Changes in the chemical composition after 9-month storage for the different storage variants

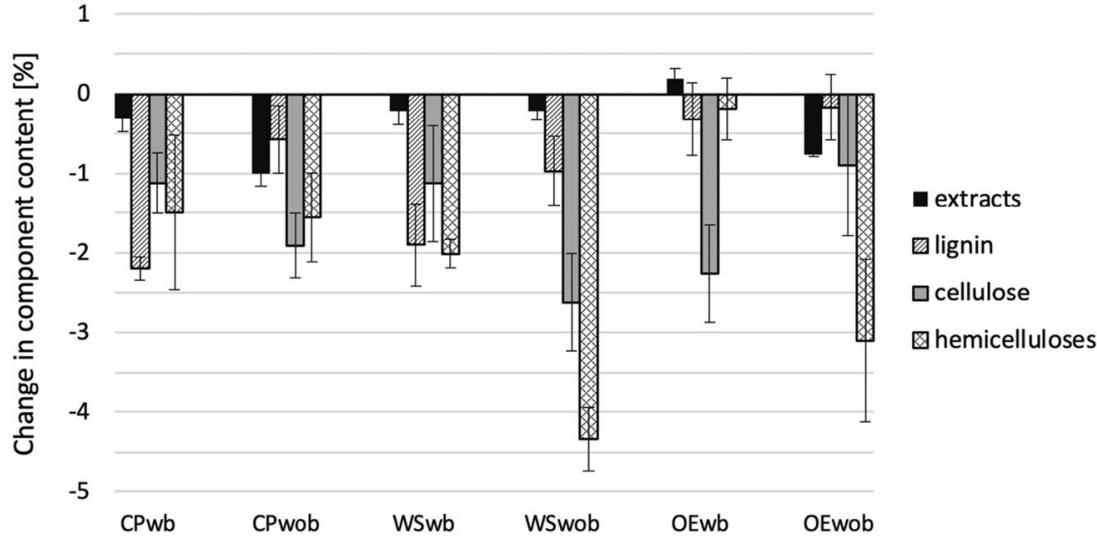

moisture content, equilibrium moisture content and wood density $\left(\rho_{0}\right)$. In this context, vaporization of volatile substances is likely. This may have led to a substantial loss of these components and applies in particular for the amount of extractives. Nevertheless, this is a standard protocol which was applied to all specimens, so comparability between the samples is still accurate.

Repeated measurement for each bulk sample is a compromise between accuracy and labour intensity. Furthermore it indicates an error range, which makes it possible to set the results in context.

\section{Influence of Wood Moisture Content}

Regarding log storage, fungi infestation is considered as the most important risk for wood degradation and the related loss of value $[14,17]$. The aim of storage concepts is to store logs in conditions unfavourable for wood-degrading fungi. Two different strategies are applied, both using WMC as the main monitoring parameter. Hereof wood moisture contents of well over $100 \%$ or below fibre saturation $(<30 \%)$ are considered optimal $[17,23,35,36]$.

During the investigations carried out, similar wood moisture content at the beginning resulted in different moisture levels at the end of the storage period, as expected, depending on the variant. As for storage under oxygen exclusion, water sprinkling and dry storage without bark, the poplar logs were stored in a wood moisture content stated as ideal high $(>150 \%$ $\mathrm{WMC})$ or low $(<30 \% \mathrm{WMC})$ over the entire storage period. Noticeable is the reduction of WMC between the first and second additional sampling for storage with water sprinkling (WSwb, $187>155 \%$; WSwob, $214>185 \%$ ). This could be explained by the development of strong shoots growing from the logs, so that less water reached the surface of the total pile. Additionally, these shoots represent at least partially living structures of the logs with active water uptake (Fig. 6). This could have an impact on the WMC. Changes between the additional sampling dates confirm the independency of WMC from weather conditions for this storage method.
The dry and warm weather conditions in 2018 led to a quick and significant reduction of WMC in the logs stored under drying conditions. For CPwob a WMC of $17 \%$ was achieved within 10 weeks of storage. In contrast, logs stored in compact piles with bark remained in a critical moisture level for a notably longer time, reaching an average of $38 \%$ within 8 weeks. Nevertheless, higher WMC values (CPwb, 98\%; CPwob, 35\%) were measured during second additional sampling for both variants in October due to increased precipitation in the weeks prior the sampling. This indicates a faster remoistening for the logs with bark. Furthermore, debarked logs remained on a lower level throughout the whole storage period, as indicated by additional sampling.

The standard deviation of WMC at SoS for all piles was low and homogeneous. This changed during storage, whereby similar levels of heterogeneity were observed for AS and EoS, depending on the storage variant, despite the different sampling methods. This refers to different moisture levels inside the pile, displayed by adapted sampling locations. The standard deviation for CPwob remains notably low, indicating homogeneous conditions, most likely depending on the smaller pile size.

The presented development of WMC suggests a higher risk of fungal decay with the associated changes in wood properties for $\mathrm{CPwb}$ compared to the other variants. In order to illustrate the influence of the storage variant on the investigated wood properties, they were ranked based on the calculated effect size according to Pearson's $r$, and grouped ranking was applied for the chemical changes (Table 6). The ranking shows how strong the wood properties are affected by the storage conditions whereby higher values indicate higher effects. Lower numbers in total impact are associated with a favourable storage variant. The disparity between indicated risk by wood moisture content and actual changes in wood properties emerges.

Besides WMC being the main driver for the possibility of fungi infestation, changes in wood density and therefore dry mass loss are the key indicators to evaluate the final storage success. 
Fig. 6 Logs with strong growing shoots after 6 months of storage under water sprinkling

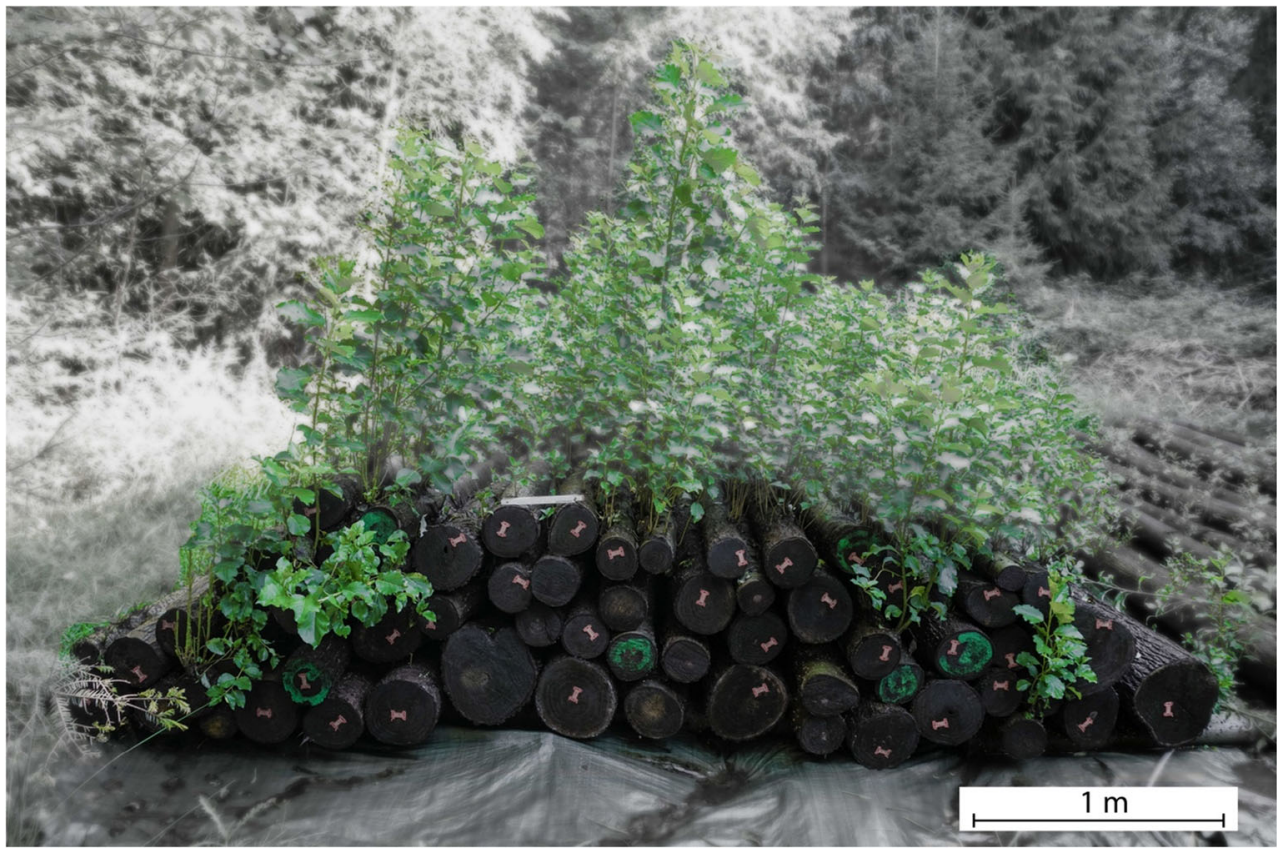

\section{Log Storage Under Dry Conditions}

Despite the assumption of the high risk regarding the development of WMC in the compact pile with bark, the dry mass loss was relatively low, whereas the one without bark showed the expected influence, according to the fast drying. Resulting density changes ( $4.81 \%$ and $5.02 \%$, respectively) display similar dry matter losses (up to $7 \%$ ) which were observed by other researches for poplar stems stored for 6 and 7 months from SRC $[9,13]$.

Since the deficit of precipitation in May led to fast reduction in WMC, initial infestation by fungi was moderate. Despite this, a common set of species responsible for wood decay [37] could be found in the wood but without remarkable development. Due to their ability to endure periods with dry conditions after initial settlement [37], infestation was possible. Thin sections showed hyphae in different locations and intensities, but it remains unclear how deep the hyphae were able to penetrate the tissue and how strong fungal decay took place in each $\log$, while the resulting dry mass loss was fairly low. Most certainly longer storage periods would promote further fungal decay and result in higher dry mass losses [14]. Proportional degradation in all chemical wooden components were as expected, but on a substantially lower level and led to only slight changes in physical properties. This suggests normal microbial decomposition without structural change for log storage under dry conditions. The correlation between changes in polysaccharides, esp. hemicelluloses and EMC, support this assumption, since hydrophilic groups get degraded by fungal decay $[17,38]$.

\section{Log Storage with Water Sprinkling}

Absence of oxygen in the piles with water sprinkling should have been attained by constant uptake of water, which is associated with a lower risk of decay $[14,19]$. In contrast, the observed changes in wood density and chemical properties were higher than assumed, especially for debarked logs. Glucosidases generally work under anaerobic conditions in an energetically inefficient manner, and therefore degradation
Table 6 Ranked impact by effect size, based on Pearson's $r$ for wood density $\left(\rho_{0}\right)$ and EMC, grouped ranking for chemical changes ( 1 , low changes; 2 , medium changes; 3 , high changes)

\begin{tabular}{lllllll}
\hline & CPwb & CPwob & WSwb & WSwob & OEwb & OEwob \\
\hline WMC during storage & Medium & Low & High & High & High & High \\
Indicated risk & High & Low & Low & Low & Low & Low \\
Wood density $\left(\rho_{0}\right)$ & 4 & 3 & 5 & 6 & $0 *$ & $0 *$ \\
EMC & 1 & 4 & 2 & 3 & 5 & 6 \\
Chemistry & 2 & 2 & 2 & 3 & 1 & 1 \\
Total impact & 7 & 9 & 9 & 11 & 6 & 7 \\
\hline
\end{tabular}

*No significant differences 
should be slower [39]. On the other hand, water is required for the enzymatic cleavage of the glyosidic bond [18], which could explain a higher degradation of hemicelluloses. Since microbial lignin degradation is always associated with oxygen availability, the assumption of completely anaerobic conditions during water sprinkling storage cannot be retained. Additionally, fungi fruit bodies were found on the piles with water sprinkling, and unpleasant smell during the sampling refers to other microbial activity, such as bacteria. Since substantial degradation of cellulose and hemicelluloses was observed, the involved bacteria might belong to the group of erosion bacteria [18]. For the contribution of fungi to wood decay in water sprinkled piles, several investigations on spruce found a massive infestation of Armillaria (spec.) in the logs [40-42]. Therefore, a fungal involvement cannot be completely prevented. Minor loss in lignin may also occur due to elution processes from the water running through the piles [18].

\section{Log Storage Under Oxygen Exclusion}

Although there were slight changes in wood density for logs under oxygen exclusion, no significant differences were found. In contrast to the piles with water sprinkling, for those inside the film, evidence of oxygen exclusion could be assured by the measurements of gas atmosphere. The decrease of $\mathrm{CO}_{2}$ concentration could be explained by diffusion through the silage film. The diffusion rate is four times higher than for $\mathrm{O}_{2}$, which is entering the package but gets transformed immediately by respiration [26]. Missing lignin loss for these piles confirms the described dependence of degradation on oxygen availability. Perhaps high temperatures inside the wrapped log piles led to formation of esters [43], capable of degrading hemicelluloses. The disproportional decrease in extract substances can essentially be explained by the release of volatile components such as mono- and sesquiterpenes, because storage without bark favours the release of these substances [18]. Furthermore, there is the possibility a weak acid based on $\mathrm{CO}_{2}$ dissolving in water occurs, which could result in depolymerization of cellulose and hemicellulose [44]. Substantial reduction of cellulose in OEwb may have led to measurement of degraded cellulose remains, which led to a higher estimation of hemicelluloses at the end of storage, reducing the detection of the actual loss.

However, drastic changes in the chemical composition were observed in the WS storage, especially without bark. The amorphous structure of the hemicelluloses may contribute to the greatest degradation under these conditions.

Nevertheless, changes in wood density throughout the storage period indicate a minor fungal influence on the dry mass loss than expected. Regarding the piles under moist conditions, other microbial factors, such as bacteria, should be taken into account $[16,18,45]$, since the observed dry mass losses and changes in chemical components can barely be explained by exclusive fungal activity.

\section{Conclusions}

In association with material utilization of poplar wood from SRC, it is essential to implement suitable storage methods to ensure a continuous supply. For this purpose, the study presents and compares potential courses of action.

Considering the weather conditions in the investigated period and chosen experimental setup, specifically the pile dimensions, storage in compact piles, especially with debarked $\operatorname{logs}$, is the best method for the preservation of poplar wood from SRC. Technological demand and thus financial expense regarding dry mass loss and changes in chemical composition are highly beneficial for these short storage periods. Additionally, it has less restrictions regarding the location and avoids the necessity of permissions by local water authorities for the water sprinkling, which would led to additional administrative expenses. In comparison with the storage under oxygen exclusion, no additional waste is produced by the use of film. Also, a maintenance for monitoring of the gas atmosphere is not required.

Indication of changes in wood properties by WMC was deficient for most observed variants.

Due to the short duration of storage with exceptionally dry and warm weather conditions in 2018, the results are limited in general validity.

To validate the conclusions for storage in moist conditions, further investigation regarding microbial activity and resulting wood decay is necessary.

The final decision on the optimal storage method should be made by the trade-offs between risks and costs.

Acknowledgements The authors would like to thank the Chair of Meteorology, Technische Universität Dresden, for providing the weather data.

Funding Open Access funding enabled and organized by Projekt DEAL. The study was carried out as part of the Dendromass4Europe project. This project has received funding from the Bio Based Industries Joint Undertaking under the European Union's Horizon 2020 research and innovation programme under grant agreement no. 745874 .

Data Availability The data that support the findings of this study are available from the corresponding author, upon reasonable request.

\section{Compliance with Ethical Standards}

Conflict of Interest The authors declare that they have no conflict of interest.

Ethics Approval and Consent to Participate Not applicable 
Consent for Publication Not applicable

\section{Code Availability Not applicable}

Abbreviations SoS, start of storage; EoS, end of storage; CP, compact pile; $\mathrm{CPwb}$, compact pile with bark; CPwob, compact pile without bark; WS, water sprinkling; WSwb, water sprinkling with bark; WSwob, water sprinkling without bark; OE, oxygen exclusion; OEwb, storage under oxygen exclusion with bark; OEwob, storage under oxygen exclusion without bark; AS, additional sampling (24.05.2018/10.10.2018); WMC, wood moisture content; EMC, equilibrium moisture content; SRC, shortrotation coppice

Open Access This article is licensed under a Creative Commons Attribution 4.0 International License, which permits use, sharing, adaptation, distribution and reproduction in any medium or format, as long as you give appropriate credit to the original author(s) and the source, provide a link to the Creative Commons licence, and indicate if changes were made. The images or other third party material in this article are included in the article's Creative Commons licence, unless indicated otherwise in a credit line to the material. If material is not included in the article's Creative Commons licence and your intended use is not permitted by statutory regulation or exceeds the permitted use, you will need to obtain permission directly from the copyright holder. To view a copy of this licence, visit http://creativecommons.org/licenses/by/4.0/.

\section{References}

1. Schubert R, Schellnhuber HJ, Buchmann N, Epiney A, Grießhammer R, Kulessa M, Messner D, Rahmstorf S, Schmid J (2009) Future bioenergy and sustainable land use. German Advisory Council on Global Change (WGBU), Earthscan, Sterling, London

2. González-García S, Bacenetti J (2019) Exploring the production of bio-energy from wood biomass. Italian case study. Sci Total Environ 647:158-168

3. Sims R, Hastings A, Schlamadinger B, Taylor G, Smith P (2006) Energy crops: current status and future prospects. Glob Chang Biol 12(11):2054-2076

4. Global Bioeconomy Summit (2015) Communiqué of the Global Bioeconomy Summit 2015 / Making bioeconomy work for sustainable development. http://gbs2015.com/fileadmin/gbs2015/ Downloads/Communique_final.pdf, Berlin, November 2015 accessed June 2020

5. Friese F, Euring M, Kharazipour A (2015) Particleboards from newly exploited wood sources as a starting point for cascade utilisation. In: Manning DB, Bemmann A, Bredemeier M, Lamersdorf N, Ammer C (eds) Bioenergy from dendromass for the sustainable development of rural areas. Wiley, Weinheim, pp 497-507

6. Nord-Larsen T, Talbot B (2004) Assessment of forest-fuel resources in Denmark: technical and economic availability. Biomass Bioenergy 27(2):97-109

7. Idler C, Pecenka R, Lenz H (2019) Influence of the particle size of poplar wood chips on the development of mesophilic and thermotolerant mould during storage and their potential impact on dry matter losses in piles in practice. Biomass Bioenergy 127:105273

8. Pari L, Brambilla M, Bisaglia C, Giudice A, Croce S, Salerno M, Gallucci F (2015) Poplar wood chip storage: effect of particle size and breathable covering on drying dynamics and biofuel quality. Biomass Bioenergy 81:282-287

9. Civitarese V, Spinelli R, Barontini M, Gallucci F, Santangelo E, Acampora A, Scarfone A, Giudice A, Pari L (2015) Open-air drying of cut and windrowed short-rotation poplar stems. Bioenerg Res 8(4):1614-1620

10. Rademacher P, Hapla F, Leder B (2011) Investigations of wood conservation in spruce logs after storage under plastic foil. Part I: Time series of climatic and environmental parameters of the stored wood. Forstarchiv 82(1):3-9

11. Rademacher P, Hapla F (2012) Investigations of wood conservation in spruce logs after storage under plastic foil. Part II: Physical and elasto-mechanical properties of the produced sawn-timber. Forstarchiv 83(4):144-154

12. Wauer A, ,Kubatta-Große M, Lutze M (2013) Verfahren der Rundholzlagerung. In: Berichte der Bayerischen Landesanstalt für Wald und Forstwirtschaft, LWF Wissen 71

13. Pecenka R, Lenz H, Hering T (2020) Options for optimizing the drying process and reducing dry matter losses in whole-tree storage of poplar from short-rotation coppices in Germany. Forests 11:374

14. STODAFOR (2004) Technical guide on harvesting and conservation of storm damaged timber. Joint FAO/ECE/ILO Committee on Forest Technology, Management and Training, CTBA, Paris

15. Eriksson K-L, Blanchette RA, Ander P (1990) Microbial and enzymatic degradation of wood and wood components. Springer Series in Wood Science. Springer-Verlag, Berlin

16. Greaves H (1971) The bacterial factor in wood decay. Wood Sci Technol 5:6-16

17. Huckfeldt T, Rehbein M (2017) Bakterien und Pilze an WasserbauHolz. Institut für Holzqualität und Holzschäden, Dr. Rehbein und Dr. Huckfeldt GbR, Hamburg

18. Nilsson N (2009) Biological wood degradation. In: Ek M, Gellerstedt G, Henriksson G (eds) Wood chemistry and biotechnology. De Gruyter, Berlin, pp 219-244

19. DIN EN 350 (2016-12) Dauerhaftigkeit von Holz und Holzprodukten - Prüfung und Klassifizierung der Dauerhaftigkeit von Holz und Holzprodukten gegen biologischen Angriff; Deutsche Fassung EN 350:2016, Beuth, Berlin

20. Lenz H, Pecenka R, Idler C, Dumfort S, Whittaker C, Ammon C, Hartung E (2017) Continuous weighing of a pile of poplar wood chips - a comparison of methods to determine the dry matter losses during storage. Biomass Bioenergy 96:119-129

21. Barontini M, Crognale S, Scarfone A, Gallo P, Gallucci F, Petruccioli M, Pesciaroli L, Pari L (2014) Airborne fungi in biofuel wood chip storage sites. Int Biodeterior Biodegradation 90:17-22

22. Pecenka R, Lenz H, Idler C (2018) Influence of the chip format on the development of mass loss, moisture content and chemical composition of poplar chips during storage and drying in open-air piles. Biomass Bioenergy 116:140-150

23. Schwarze FWMR, Engels J, Mattheck C (1999) Holzzersetzende Pilze in Bäumen. Bd. 5, Rombach, Freiburg, Germany

24. Fachagentur Nachwachsende Rohstoffe (2020) Rahmenvereinbarung für den Rohholzhandel in Deutschland (RVR). FNR2020, 3. aktualisierte Auflage, 1. Juli 2020

25. Riegger W (2008) Industrieholz: Ist die Werksvermessung genau genug? Wald und Holz 89(2):1-3

26. Maier T (2005) Konservierung von Rundholz unter Sauerstoffabschluss - Folienkonservierung. Dissertation Universität Freiburg

27. DIN EN 13183-1 (2002) Feuchtegehalt eines Stückes Schnittholz Teil 1: Bestimmung durch Darrverfahren. Deutsche Fassung EN 13183-1:2002-07, Beuth, Berlin, Germany

28. DIN 52182 (1976) Prüfung von Holz; Bestimmung der Rohdichte. DIN 52182:1976-09, Beuth, Berlin, Germany

29. DIN 50014 (2018) Normalklimate für Vorbehandlung und/oder Prüfung - Festlegungen. DIN 50014:2018-08, Beuth, Berlin, Germany

30. Technical Association of the Pulp and Paper Industry (1997) TAPPI T $204 \mathrm{~cm}$ 97: solvent extractives of wood and pulp. TAPPI 
31. Technical Association of the Pulp and Paper Industry (1975) TAPPI T $249 \mathrm{~cm}$ 75: carbohydrate composition of extractive-free wood and wood pulp by gas-liquid chromatography. TAPPI

32. Kürschner K, Hoffer A (1931) Eine neue quantitative Cellulosebestimmung. Chemiker-Zeitung 17:161-168

33. Lenz H, Pecenka R, Hartung E, Idler C (2016) Development and test of a simplified method to calculate dry matter loss during openair storage of poplar wood chips by analysing ash contents. Biomass Bioenergy 94:258-267

34. Liu N, Larsen SU, Jørgensen U, Murach D, Pflugmacher C, Hartmann H, Lærke PE (2017) Combustion quality of poplar and willow clones grown as SRC at four sites in Brandenburg, Germany. Biomass Bioenergy 106:51-62

35. Arnold M (1993) GBasic and organizational aspects of the storage of round wood. Schweizerische Zeitschrift für Forstwesen, Journal forestier suisse 144(11):843-858

36. Liese W, Ammer U (1968) Lagerschäden an Rundholz. Biologische Grundlagen und Möglichkeiten der Verhütung. Forst-u Holzwirt 23(13):265-267

37. Scheiding W, Grabes P, Haustein T, Haustein V, Nieke N, Urban H, Weiß B (2016) Holzschutz: Holzkunde-Pilze und InsektenKonstruktive und chemische Maßnahmen-Technische RegelnPraxiswissen. Carl Hanser Verlag GmbH Co KG, Leipzig, Germany
38. Béguin P, Aubert J-B (1994) The biological degradation of cellulose. FEMS Microbiol Rev 13(1):25-58

39. Bischofsberger W, Dichtl N, Rosenwinkel KH, Seyfried CF, Böhnke B (2005) Anaerobtechnik. Springer-Verlag, Berlin Heidelberg

40. Groß M, Metzler B (1995) Auftreten und Ausbreiten von Hallimasch in Beregnungspoltern. Holz Roh Werkst 53(95):147153

41. Schumacher P, Grosser D (1995) Befall länger beregneten Fichtenstammholzes durch Hallimasch (Armillaria spp.) und sonstige Holzpilze. Holz Roh Werkst 53(95):137-145

42. Engesser R (2003) Pilzbefall an nassgelagertem "Lothar"Rundholz. Wald und Holz 11(03):52-56

43. Navi P, Sandberg D (2012) Thermo-hydro-mechanical processing of wood. EPFL Press, Lausanne

44. Unger A, Schniewind AP, Unger W (2001) Corrosion behavior of wood. In: Conservation of wood artifacts. Natural Science in Archaeology. Springer, Berlin, Heidelberg, Germany

45. Seifert K (1967) Über den Holzabbau durch Bakterien. Holz Roh Werkst 25(10):377-379

Publisher's Note Springer Nature remains neutral with regard to jurisdictional claims in published maps and institutional affiliations. 